\title{
The primary care and other health system use of home care patients: a retrospective cohort analysis
}

\author{
Aaron Jones MSc, Susan E. Bronskill PhD, Gina Agarwal MBBS PhD, Hsien Seow PhD, \\ David Feeny PhD, Andrew P. Costa PhD
}

\section{Abstract}

Background: Robust and integrated primary care and home care are core components of effective chronic disease management in the community. We described the primary care and other health system use by a cohort of home care patients.

Methods: We conducted a population-based retrospective cohort study of patients who received publicly funded home care in Ontario, Canada, from October 2014 to September 2016. Primary outcomes were primary care physician visits including coordination with home care, home visits and visits after hours or on weekends or holidays within 6 months of a home care assessment. Secondary outcomes included specialist physician visits, emergency department use, home care visits and placement in a long-term care home. Multivariable models examined associations between patient characteristics and subsequent primary care use.

Results: There were 226054 home care patients in our cohort, with a median age of 81 years. Following assessment, home care patients visited primary care physicians at a rate of 0.78 visits per month. Physician-based home care coordination codes were billed for $3.9 \%$ of patients. Primary care home visits were received by $13.1 \%$ of patients, and $15.1 \%$ of patients used primary care after hours or on weekends or holidays.

Interpretation: Patients receiving publicly funded home care frequently visited a primary care physician. Physician billings for coordination between primary care and home care were infrequent but were more common in interprofessional primary care practices. Physician home visits were more likely to be received by the oldest and most functionally impaired patients, suggesting that home visits are responsive to the needs of home care patients.

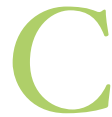
hronic disease management models frequently emphasize the importance of quality primary care for effective chronic disease management in the community. ${ }^{1-3}$ Various aspects of the delivery of primary care have been shown to improve outcomes in older adults. For example, coordination between primary care and other health sectors can reduce depressive symptoms and improve the functional status of older adults with multimorbidity. ${ }^{4}$ Home-based primary care has been shown to reduce emergency department visits and hospital admissions in homebound older adults. ${ }^{5}$ Access to timely primary care and after-hours primary care could reduce emergency department visits. ${ }^{6,7}$ However, research suggests that older adults with complex care needs frequently experience fragmentation of care and difficultly accessing primary care. ${ }^{8}$

Home care patients are a population of community-dwelling older adults characterized by multiple chronic conditions, need for support in activities of daily living and a high risk of adverse outcomes. ${ }^{910}$ Aging strategies have frequently called for robust and responsive primary care and home care to enable seniors to live well in the community as long as possible..$^{11,12}$
However, primary care use by home care patients has not been well studied.

The objective of this study was to describe the utilization of primary care physician services by patients receiving publicly funded home care in Ontario, including coordination between home care and primary care and advanced access to primary care, such as home visits and care after hours or on weekends or holidays. We examined associations between patient characteristics and subsequent primary care use and also described the use of other health sectors to contextualize our findings.

Competing interests: David Feeny is one of the copyright holders of the Health Utilities Index through a proprietary interest in Health Utilities Inc.

This article has been peer reviewed.

Correspondence to: Aaron Jones, jonesa13@mcmaster.ca

CMAJ Open 2019. DOI:10.9778/cmajo.20190038 


\section{Methods}

\section{Study design and data sources}

We identified a population-based, retrospective cohort of adults in Ontario, Canada, who received a comprehensive home care assessment and used multiple population-based health administrative databases to capture health system use following the assessment. Home care patients were identified through the Home Care Database, which captures client and service records for publicly funded home care programs in Ontario. Physician visits were extracted from the Ontario Health Insurance Plan claims database, which contains information on inpatient and outpatient physician billings, including "shadow billings" for physicians in primarily capitated payment models. As the Home Care Database and the Ontario Health Insurance Plan database form the basis for payments to health care providers, they have good completion and are regularly used in research. ${ }^{13}$ Other databases used included administrative records of hospital admissions, emergency department visits and placement in long-term care homes. A description of all data sources can be found in Appendix 1, available at www.cmajopen.ca/content/7/2/E360/ suppl/DC1. These data sets were linked using unique encoded identifiers and analyzed at ICES.

\section{Study cohort}

Publicly funded home care services are available in Ontario to people who require support to remain in their homes, typically seniors with functional impairments or other complex medical conditions. ${ }^{14}$ All publicly funded home care patients who are receiving ongoing care are periodically assessed with the Resident Assessment Instrument for Home Care (RAI-HC), a comprehensive clinical assessment tool. ${ }^{15}$ We selected all RAI-HC assessments of adult (aged $\geq 19 \mathrm{yr}$ ) home care patients completed in Ontario between Oct. 1, 2014, and Sept. 30, 2016. If a patient was assessed more than once during the period, their most recent assessment was selected. The assessment date was considered the index date for a 6-month follow-up window. Patients receiving palliative home care at baseline were excluded from the cohort as their health utilization and outcomes vary greatly from those of other home care patients.

\section{Baseline characteristics}

Patient characteristics were identified from the baseline assessment and included demographic, health and functional characteristics, frailty, ${ }^{10}$ health-related quality of life $^{16}$ and 3 key conditions known to be primary drivers of home care: congestive heart failure, chronic obstructive pulmonary disease and dementia. ${ }^{17-19}$ Similar to other studies ${ }^{20}$ we also classified each patient's primary care enrolment model at baseline. The 3 main model types are (a) family health teams, which are team-based, interprofessional primary health care organizations funded primarily through capitation payments; (b) other blended capitation models, which are funded similarly but lack the explicit interprofessional approach; and (c) enhanced fee-for-service models, which are funded primarily through billing claims. A few rural and specialty models were grouped together in an "other" category and patients not rostered to a physician were considered a distinct category.

\section{Primary care use among home care patients}

We linked the index assessment records to other health administrative databases to identify health service use within 6 months (182 d) of the assessment date. A 6-month follow-up was chosen as it aligns with the standard RAI-HC assessment interval and at least three-quarters of patients can be expected to experience a meaningful clinical change within 6 months. ${ }^{21}$ Primary care physician visits were defined as all office, home or phone-based services provided by a general practice/family practice physician or community medicine physician with a maximum of 1 visit per patient per physician per day. We identified primary care coordination with home care using billing codes specific to primary care supervision of home care or participation of a primary care physician in a case conference concerning a home care patient. For measures of advanced access, we identified primary care physician visits to a patient's home and primary care visits that occurred after hours or on a weekend or holiday. Details of the calculation of each physician measure can be found in Appendix 2, available at www.cmajopen.ca/content/7/2/E360/supp1/DC1.

\section{Other health system use among home care patients}

To contextualize the primary care use, we also measured patients' other health sector use and their transitions between care settings. Specialist physician visits were defined similarly to primary care and included all physicians other than those in general practice/family practice, community medicine and pediatrics. Home care use was measured as hours of personal support and number of home nursing visits. Other measures included unplanned emergency department visits, unplanned acute hospital admissions, long-term care home admissions and death. We also tracked the care setting of the patient (community, hospital, long-term care, dead) across the 6-month follow-up period and calculated the total number of transitions in care settings.

\section{Descriptive analysis}

We reported the proportion of patients with each type of primary care physician visit, the rate of primary care physician visits per month, the proportion of patients with any specialist physician visit, the average number of specialties seen and the rate of specialist physician visits per month. We also reported the proportion of patients who received or were authorized at baseline for personal support and home nursing as well as the rate of visits (or hours) per month among patients with the service. Other measures reported included the proportion of patients with an unscheduled emergency department visit, acute hospital admission and long-term care home admission, the rate of emergency department visits per month, the number of transitions of care settings and the proportion of patients who died during the follow-up window.

All rates were based on the number of days during follow-up that the patient spent in the community, that is, not 
dead, in a long-term care home or in hospital. The calculation of home care rates excluded any days after home care services were discharged. Monthly rates were produced by multiplying the daily rate by 30 . Additionally, the proportion of patients who received a home visit from a primary care physician was reported by functional impairment stratum and we stratified the proportion of patients with primary care coordination with home care by Ontario's 14 health regions to explore variation in the rates on the basis of regional initiatives to promote coordination. All descriptive measures were reported both for the entire cohort as well as for the important subpopulations with congestive heart failure, chronic obstructive pulmonary disease and dementia.

\section{Multivariable analysis}

We fit multivariable regression models to examine associations between patient characteristics and 4 measures of primary care use. The rate of primary care physician visits was fit with a quasi-Poisson generalized linear model ${ }^{22}$ with an offset term for days spent in the community. Primary care coordination with home care, home visits with a primary care physician, and visits with a primary care physician after hours or on weekends or holidays were each separately fit with logistic regression models. We included independent variables that we believed may be associated with primary care utilization on the basis of previous research and our own judgment. ${ }^{23,24}$ These included demographics (sex, age, region, rurality), health characteristics (functional impairment, cognitive impairment, mood symptoms, comorbid conditions, number of concurrent medications) and health services (primary care patient enrolment model type, home care services received or authorized at baseline). Results were reported as incidence rate ratios (IRRs) or odds ratios (ORs) with 95\% confidence intervals (CIs). All analyses were performed using SAS 9.4 (SAS Institute Inc.).

\section{Ethics approval}

This study was granted an exemption from formal ethics review by the Hamilton Integrated Research Ethics Board as the use of data in this project was authorized under section 45 of Ontario's Personal Health Information Protection Act, which does not require review by a research ethics board.

\section{Results}

We identified 226054 adult home care patients with an assessment between Oct. 1, 2014, and Sept. 30, 2016. The median age of patients in the cohort was 81 years and just under two-thirds (62.9\%) were women (Table 1). A total of $43.6 \%$ of patients needed at least limited assistance with personal hygiene, locomotion, eating or toileting, and $62.2 \%$ had at least a mild cognitive impairment. At baseline, 13.2\% of patients had a diagnosis of congestive heart failure at baseline, $19.6 \%$ had chronic obstructive pulmonary disease and $25.8 \%$ had a diagnosis of dementia. Roughly $30 \%$ of patients were enrolled in each of the 3 broad types of primary care patient enrolment models at baseline. Transitions
Table 1: Baseline characteristics of adult home care patients in Ontario, September 2014 to October 2016

\begin{tabular}{lc}
\hline Characteristic & No. (\%) of patients* \\
$n=226054$
\end{tabular}

\section{Demographics}

Age, yr (median Q1, Q3)

$81(71,88)$

Sex, female

83978 (62.9)

Lived alone

110137 (48.7)

Health

ADL impairment $\dagger$

\begin{tabular}{|l}
\hline Independent/supervision \\
\hline Limited/extensive \\
\hline Maximal/dependent \\
\hline Cognitive impairment $\ddagger$ \\
\hline
\end{tabular}

\begin{tabular}{l}
\hline Intact/borderline intact \\
\hline Mild/moderate
\end{tabular}

Severe

127725 (56.5)

72220 (32.0)

26109 (11.6)

Mood symptoms§

No symptoms 108918 (48.2)

Some symptoms

$59684(26.4)$

Daily symptoms

85613 (37.9)

$121081(53.6)$

$19360(8.6)$

Bladder incontinence

57452 (25.4)

Fall in last $90 \mathrm{~d}$

94535 (41.8)

$\geq 5$ concurrent medications

91962 (40.7)

Congestive heart failure

189760 (83.9)

Chronic obstructive pulmonary disease

29875 (13.2)

Dementia

44209 (19.6)

Frailty indexๆ

Robust (0-0.19)

$46043(20.4)$

Prefrail (0.2-0.29)

$68562(30.3)$

Frail $(\geq 0.3)$

$111449(49.3)$

Health-related quality of life score

(median Q1, Q3) **

Patient enrolment model

\begin{tabular}{lc} 
Enhanced fee-for-service & $73150(28.7)$ \\
\hline Family health team & $75031(32.4)$ \\
\hline Other capitation & $64908(33.2)$ \\
\hline Other & $8403(2.0)$ \\
\hline Not enrolled & $4562(3.7)$
\end{tabular}

Note: $A D L=$ activities of daily living, Q1 = quartile 1, Q3 = quartile 3.

*Unless indicated otherwise.

†Measured with the ADL Hierarchy Scale, which includes personal hygiene, locomotion, eating and toileting.

$¥$ Measured with the Cognitive Performance Scale.

§Measured with the Depression Rating Scale.

IScores on the frailty index range from 0 to 1 , where 0 represents no health deficits and 1 represents all possible health deficits. ${ }^{10}$

${ }^{* \star}$ Scores on the Health Utilities Index Mark 3 (HUI3) range from 0 to 1 , where 1 represents perfect health and 0 represents dead. The range of the values is -0.36 to 1 with scores less than 0 representing health states considered worse than dead. 
between care settings across the follow-up period were common (Figure 1). At the end of 6 months, $70.7 \%$ of the patients were still living in the community, $12.6 \%$ were in long-term care homes, $3.6 \%$ were in hospitals and $13.1 \%$ had died.

\section{Primary care use among home care patients}

The overall rate of primary care physician visits during the follow-up period was 0.78 visits per month (Table 2 ), with $84.4 \%$ of patients having at least 1 visit during the followup period. Primary care coordination with home care codes was billed for $3.9 \%$ of patients. Home visits from primary care physicians were received by $13.1 \%$ of patients, and $15.1 \%$ of patients used primary care after hours or on weekends or holidays. Patients with congestive heart failure and chronic obstructive pulmonary disease had somewhat higher primary care use than the overall population. Among the most functionally impaired patients, just over one-quarter $(27.5 \%)$ received a home visit from a primary care physician (Table 3). Stratifying primary care coordination with home care by health regions revealed significant regional variation in the use of the codes, particularly in the differential between family health teams and other patient enrolment models (Appendix 3, available at www.cmajopen.ca/content /7/2/E360/suppl/DC1).

\section{Other health system use among home care patients}

Around three-quarters of patients (71.8\%) received personal support while just over a third received home nursing $(35.7 \%)$. Nearly half of patients $(46.9 \%)$ visited the emergency department and over a quarter (27.2\%) had an unplanned hospital admission during the 6-month followup. Patients with congestive heart failure or chronic obstructive pulmonary disease had higher rates of emergency department visits, hospital admissions and death. Patients with dementia had emergency department and hospital utilization similar to that of the overall population but were significantly more likely to be admitted to a long-term care home.

\section{Multivariable analysis}

Given the number of associations examined and the power of the study to detect small effects, only statistically significant IRRs and ORs with point estimates greater than 1.25 or less than 0.8 are reported in the text. All results can be found in the tables.

\section{Rate of primary care physician visits}

Receiving home care nursing (IRR 1.34, 95\% CI 1.311.36) and having 9 or more prescription medications at

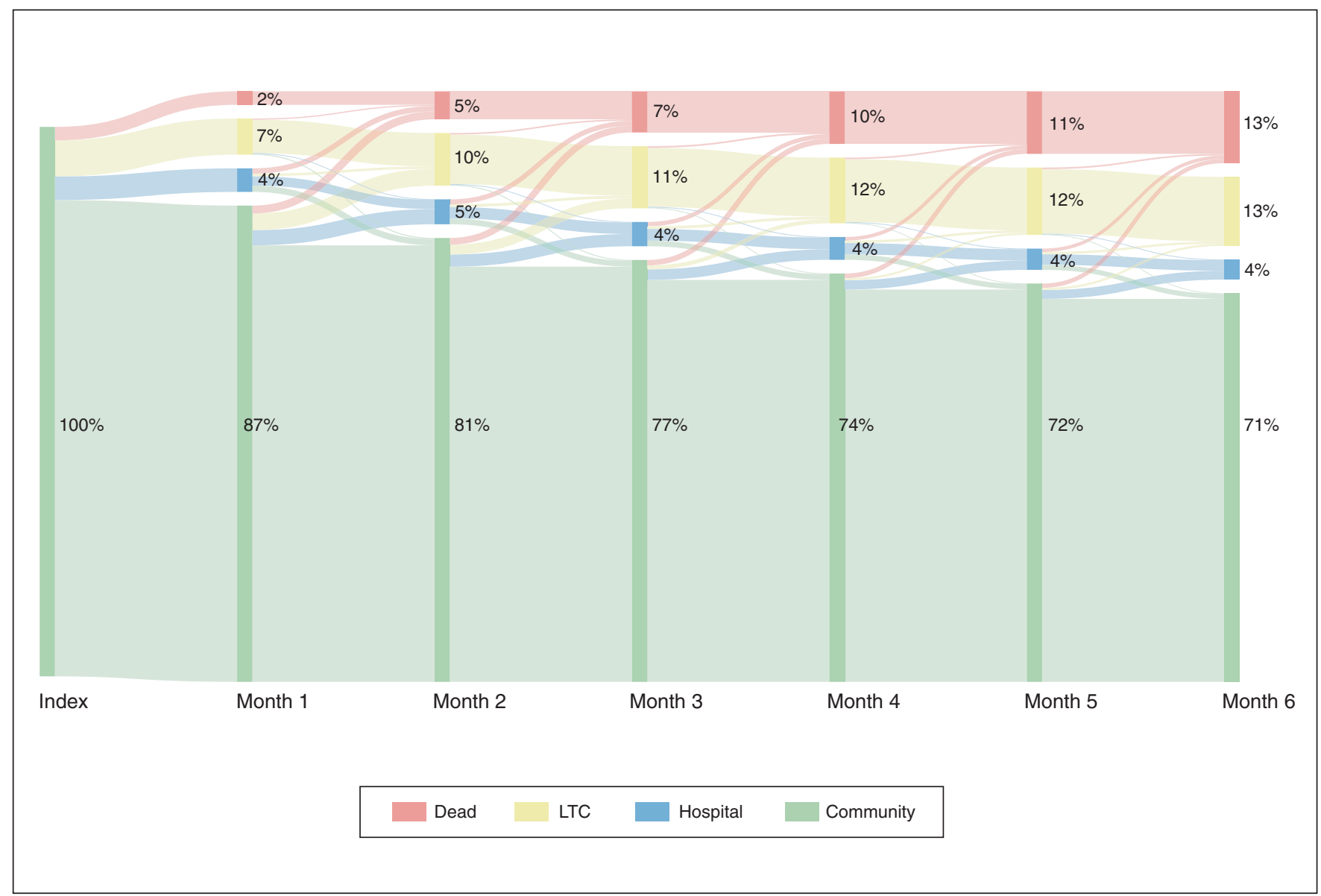

Figure 1: Transitions between care settings among adult home care patients in Ontario, September 2014 to October 2016. Note: LTC = longterm care home. 
baseline (IRR 1.38, 95\% CI 1.34-1.42) was associated with greater primary care use (Table 4). Compared with patients in enhanced fee-for-service models, patients enrolled in family health teams (IRR 0.77 , 95\% CI $0.76-$ 0.79 ), other capitated models (IRR 0.80 , 95\% CI $0.78-$ 0.82 ), other models (IRR 0.66 , 95\% CI 0.62-0.71) and patients not rostered to a physician (IRR 0.79 , 95\% CI 0.75-0.83) used less primary care.

\section{Primary care coordination with home care}

Residing in southern Ontario (OR 1.41, 95\% CI 1.34-1.48), being enrolled in a family health team (OR 2.73, 95\% CI 2.57-2.90) and receiving home care nursing (OR 3.21, 95\% CI 3.07-3.36) all increased the likelihood of primary care coordination with home care (Table 5). Patients not rostered to a physician (OR $0.66,95 \%$ CI $0.55-0.79)$ were less likely to have coordination.

Table 2: Primary care and other health system use by adult home care patients in Ontario, September 2014 to October 2016

\begin{tabular}{|c|c|c|c|c|}
\hline \multirow[b]{2}{*}{ Health system use } & \multirow{2}{*}{$\begin{array}{c}\text { Total no. (\%) of } \\
\text { patients } \\
n=226054\end{array}$} & \multicolumn{3}{|c|}{ No. $(\%)$ of patients; chronic condition } \\
\hline & & $\begin{array}{c}\text { Heart failure } \\
n=29875\end{array}$ & $\begin{array}{c}\text { COPD } \\
n=44209\end{array}$ & $\begin{array}{c}\text { Dementia } \\
n=58413\end{array}$ \\
\hline \multicolumn{5}{|l|}{ Primary care } \\
\hline Any primary care physician visit & $190777(84.4)$ & $25596(85.7)$ & $37867(85.7)$ & $47872(82.0)$ \\
\hline Rate of primary care physician visits per month & 0.78 & 0.94 & 0.86 & 0.79 \\
\hline Any primary care coordination with home care & $8918(3.9)$ & $1509(5.1)$ & $2079(4.7)$ & $2048(3.5)$ \\
\hline Any primary care physician home visit & $29532(13.1)$ & $4873(16.3)$ & $5953(13.5)$ & $8623(14.8)$ \\
\hline $\begin{array}{l}\text { Any primary care visit after hours or on weekends } \\
\text { or holidays }\end{array}$ & $34071(15.1)$ & $4542(15.2)$ & $6705(15.2)$ & $7690(13.2)$ \\
\hline \multicolumn{5}{|l|}{ Other health sectors } \\
\hline Any specialist physician visit & $154007(68.1)$ & $21163(70.8)$ & $31109(70.4)$ & $32433(55.5)$ \\
\hline Rate of specialist visits per month & 0.60 & 0.70 & 0.64 & 0.42 \\
\hline Average count of specialties seen & 1.50 & 1.64 & 1.62 & 1.00 \\
\hline Any personal support & $162276(71.8)$ & $23213(77.7)$ & $32643(73.8)$ & $45845(78.5)$ \\
\hline Any home nursing & $80636(35.7)$ & $13836(46.3)$ & $18334(41.5)$ & $14284(24.5)$ \\
\hline Rate of personal support hours per month & 22.3 & 23.4 & 20.4 & 29.3 \\
\hline Rate of home nursing visits per month & 6.8 & 6.3 & 6.1 & 5.1 \\
\hline Any emergency department visit & $105909(46.9)$ & $17461(58.4)$ & $24316(55.0)$ & $27263(46.7)$ \\
\hline Any acute care hospital admission & $61598(27.2)$ & $12011(40.2)$ & $15148(34.3)$ & $16154(27.7)$ \\
\hline Long-term care home admission & $35484(15.7)$ & $4631(15.5)$ & 5909 (13.4) & $19896(34.1)$ \\
\hline Death & $29843(13.2)$ & $6930(23.2)$ & $7633(17.3)$ & $8577(14.7)$ \\
\hline Rate of emergency department visits per month & 0.17 & 0.25 & 0.23 & 0.15 \\
\hline \multicolumn{5}{|l|}{ Transitions between care settings $\dagger$} \\
\hline 0 & $136627(60.4)$ & $14923(50.0)$ & $24876(56.3)$ & $27728(47.5)$ \\
\hline $1-2$ & $64222(28.4)$ & $10053(33.7)$ & $12980(29.4)$ & $23792(40.7)$ \\
\hline$\geq 3$ & $25205(11.2)$ & $4900(16.4)$ & $6353(14.4)$ & $6893(11.8)$ \\
\hline
\end{tabular}

Table 3: Receipt of home visits from a primary care physician, by functional impairment stratum

\begin{tabular}{|lcc|}
\hline Stratum of ADL impairment & $\begin{array}{c}\text { Total no. of patients } \\
n=226054\end{array}$ & $\begin{array}{c}\text { No. (\%) of patients who received home } \\
\text { visits from a primary care physician }\end{array}$ \\
\hline Independent/supervision & 127725 & $11883(9.3)$ \\
\hline Limited/extensive & 72220 & $10471(14.5)$ \\
\hline Maximal/dependent & 26109 & $7178(27.5)$ \\
\hline Note: $\mathrm{ADL}=$ activities of daily living. & & \\
\hline
\end{tabular}




\section{Table 4: Multivariable quasi-Poisson regression of primary care physician visits}

\begin{tabular}{|c|c|c|c|}
\hline Variable & No. of patients & $\begin{array}{l}\text { Unadjusted incidence rate ratio } \\
\qquad(95 \% \mathrm{Cl})\end{array}$ & $\begin{array}{l}\text { Adjusted incidence rate ratio } \\
\qquad(95 \% \mathrm{Cl})\end{array}$ \\
\hline \multicolumn{4}{|l|}{ Sex } \\
\hline Female & 83978 & $0.97(0.96-0.99)$ & $0.97(0.95-0.98)$ \\
\hline \multicolumn{4}{|l|}{ Age, yr } \\
\hline $19-59$ & 23520 & 1.00 (ref.) & 1.00 (ref.) \\
\hline $60-69$ & 25957 & $1.07(1.03-1.11)$ & $1.02(0.98-1.05)$ \\
\hline $70-79$ & 47410 & $1.11(1.07-1.15)$ & $1.08(1.05-1.12)$ \\
\hline $80-89$ & 86717 & $1.14(1.10-1.17)$ & $1.15(1.11-1.18)$ \\
\hline$\geq 90$ & 42450 & $1.17(1.13-1.21)$ & $1.20(1.16-1.25)$ \\
\hline \multicolumn{4}{|l|}{ Region* } \\
\hline Central & 93217 & 1.00 (ref.) & 1.00 (ref.) \\
\hline East & 42276 & $0.94(0.91-0.96)$ & $0.96(0.94-0.99)$ \\
\hline North & 19392 & $0.82(0.79-0.85)$ & $0.84(0.81-0.87)$ \\
\hline South & 71169 & $1.09(1.06-1.11)$ & $1.07(1.05-1.09)$ \\
\hline \multicolumn{4}{|l|}{ Rurality† } \\
\hline Rural & 30584 & $0.88(0.86-0.91)$ & $0.96(0.94-0.99)$ \\
\hline \multicolumn{4}{|l|}{ Patient enrolment model type } \\
\hline Enhanced fee-for-service & 73150 & 1.00 (ref.) & 1.00 (ref.) \\
\hline Family health team & 75031 & $0.78(0.76-0.79)$ & $0.77(0.76-0.79)$ \\
\hline Other capitation & 64908 & $0.81(0.79-0.82)$ & $0.80(0.78-0.82)$ \\
\hline Other & 8403 & $0.60(0.56-0.65)$ & $0.66(0.62-0.71)$ \\
\hline Not enrolled & 4562 & $0.77(0.73-0.81)$ & $0.79(0.75-0.83)$ \\
\hline \multicolumn{4}{|l|}{ Home care services } \\
\hline Personal support & 162276 & $1.00(0.89-1.02)$ & $0.98(0.96-1.00)$ \\
\hline Nursing & 80636 & $1.33(1.31-1.35)$ & $1.34(1.31-1.36)$ \\
\hline \multicolumn{4}{|l|}{ Function } \\
\hline Independent/supervision & 127725 & 1.00 (ref.) & 1.00 (ref.) \\
\hline Mild/moderate impairment & 72220 & $1.05(1.03-1.07)$ & $1.01(0.99-1.03)$ \\
\hline Severe impairment & 26109 & $1.15(1.12-1.19)$ & $1.05(1.02-1.08)$ \\
\hline \multicolumn{4}{|l|}{ Cognition } \\
\hline Independent/supervision & 85613 & 1.00 (ref.) & 1.00 (ref.) \\
\hline Mild/moderate impairment & 121081 & $1.01(0.99-1.03)$ & $0.98(0.97-1.00)$ \\
\hline Severe impairment & 19360 & $1.00(0.96-1.04)$ & $0.97(0.93-1.01)$ \\
\hline \multicolumn{4}{|l|}{ Mood } \\
\hline No symptoms & 108918 & 1.00 (ref.) & 1.00 (ref.) \\
\hline Some symptoms & 59684 & $1.11(1.09-1.13)$ & $1.10(1.08-1.13)$ \\
\hline Daily symptoms & 57452 & $1.23(1.20-1.25)$ & $1.22(1.19-1.24)$ \\
\hline \multicolumn{4}{|l|}{ Chronic conditions } \\
\hline Congestive heart failure & 29875 & $1.24(1.21-1.27)$ & $1.12(1.09-1.14)$ \\
\hline $\begin{array}{l}\text { Chronic obstructive } \\
\text { pulmonary disease }\end{array}$ & 44209 & $1.14(1.11-1.16)$ & $1.07(1.05-1.09)$ \\
\hline Dementia & 58413 & $1.02(0.99-1.04)$ & $1.04(1.02-1.07)$ \\
\hline \multicolumn{4}{|l|}{ No. of medications } \\
\hline $0-4$ & 36294 & 1.00 (ref.) & 1.00 (ref.) \\
\hline $5-8$ & 70698 & $1.21(1.17-1.24)$ & $1.17(1.14-1.21)$ \\
\hline$\geq 9$ & 119062 & $1.45(1.41-1.49)$ & $1.38(1.34-1.42)$ \\
\hline
\end{tabular}


Table 5: Multivariable logistic regression of primary care coordination with home care

\begin{tabular}{|c|c|c|c|}
\hline Variable & No. of patients & $\begin{array}{l}\text { Unadjusted odds ratio } \\
\qquad(95 \% \mathrm{Cl})\end{array}$ & $\begin{array}{c}\text { Adjusted odds ratio } \\
(95 \% \mathrm{Cl})\end{array}$ \\
\hline \multicolumn{4}{|l|}{ Sex } \\
\hline Female & 83978 & $0.92(0.88-0.96)$ & $1.01(0.96-1.06)$ \\
\hline \multicolumn{4}{|l|}{ Age, yr } \\
\hline $19-59$ & 23520 & 1.00 (ref.) & 1.00 (ref.) \\
\hline $60-69$ & 25957 & $1.03(0.94-1.12)$ & $0.94(0.86-1.03)$ \\
\hline $70-79$ & 47410 & $1.02(0.94-1.10)$ & $1.01(0.93-1.10)$ \\
\hline $80-89$ & 86717 & $0.94(0.88-1.02)$ & $1.02(0.95-1.11)$ \\
\hline$\geq 90$ & 42450 & $0.93(0.86-1.01)$ & $1.02(0.93-1.12)$ \\
\hline \multicolumn{4}{|l|}{ Region* } \\
\hline Central & 93217 & 1.00 (ref.) & 1.00 (ref.) \\
\hline East & 42276 & $1.07(1.01-1.14)$ & $0.95(0.89-1.01)$ \\
\hline North & 19392 & $1.23(1.14-1.33)$ & $1.11(1.02-1.20)$ \\
\hline South & 71169 & $1.38(1.31-1.45)$ & $1.41(1.34-1.48)$ \\
\hline \multicolumn{4}{|l|}{ Rurality† } \\
\hline Rural & 30584 & $1.29(1.22-1.37)$ & $1.06(1.00-1.13)$ \\
\hline \multicolumn{4}{|l|}{ Patient enrolment model type } \\
\hline Enhanced fee-for-service & 73150 & 1.00 (ref.) & 1.00 (ref.) \\
\hline Family health team & 75031 & $2.81(2.66-2.98)$ & $2.73(2.57-2.90)$ \\
\hline Other capitation & 64908 & $1.23(1.16-1.32)$ & $1.24(1.16-1.32)$ \\
\hline Other & 8403 & $0.90(0.74-1.10)$ & $0.87(0.70-1.07)$ \\
\hline Not enrolled & 4562 & $0.66(0.55-0.79)$ & $0.66(0.55-0.79)$ \\
\hline \multicolumn{4}{|l|}{ Home care services } \\
\hline Personal support & 162276 & $1.01(0.97-1.06)$ & $1.18(1.12-1.25)$ \\
\hline Nursing & 80636 & $3.18(3.04-3.32)$ & $3.21(3.07-3.36)$ \\
\hline \multicolumn{4}{|l|}{ Function } \\
\hline Independent/supervision & 127725 & 1.00 (ref.) & 1.00 (ref.) \\
\hline Mild/moderate impairment & 72220 & $1.11(1.06-1.16)$ & 1.06 \\
\hline Severe impairment & 26109 & $1.27(1.19-1.35)$ & 1.06 \\
\hline \multicolumn{4}{|l|}{ Cognition } \\
\hline Independent/supervision & 85613 & 1.00 (ref.) & 1.00 (ref.) \\
\hline Mild/moderate impairment & 121081 & $0.88(0.84-0.92)$ & 0.94 \\
\hline Severe impairment & 19360 & $0.90(0.83-0.97)$ & 1.00 \\
\hline \multicolumn{4}{|l|}{ Mood } \\
\hline No symptoms & 108918 & 1.00 (ref.) & 1.00 (ref.) \\
\hline Some symptoms & 59684 & $1.13(1.07-1.19)$ & $1.12(1.06-1.18)$ \\
\hline Daily symptoms & 57452 & $1.19(1.13-1.25)$ & $1.17(1.11-1.24)$ \\
\hline \multicolumn{4}{|l|}{ Chronic conditions } \\
\hline Congestive heart failure & 29875 & $1.36(1.28-1.44)$ & $1.08(1.01-1.14)$ \\
\hline $\begin{array}{l}\text { Chronic obstructive } \\
\text { pulmonary disease }\end{array}$ & 44209 & $1.26(1.20-1.33)$ & $1.06(1.04-1.12)$ \\
\hline Dementia & 58413 & $0.85(0.81-0.89)$ & $0.99(0.93-1.05)$ \\
\hline \multicolumn{4}{|l|}{ No. of medications } \\
\hline $0-4$ & 36294 & 1.00 (ref.) & 1.00 (ref.) \\
\hline $5-8$ & 70698 & $1.12(1.04-1.20)$ & $1.06(0.98-1.13)$ \\
\hline$\geq 9$ & 119062 & $1.46(1.36-1.56)$ & $1.21(1.13-1.29)$ \\
\hline
\end{tabular}




\section{Home visits from primary care physicians}

Patients in their 60s (OR 1.34, 95\% CI 1.25-1.44), in their 70s, (OR 1.80, 95\% CI 1.69-1.92), in their 80s (OR 2.63, $95 \%$ CI 2.47-2.79) and 90 years of age and older (OR 3.89, 95\% CI 3.65-4.14) were all more likely to receive a primary care home visit than younger patients (Table 6). Both personal support (OR 1.46, 95\% CI 1.41-1.51) and home nursing (OR 2.08, 95\% CI 2.02-2.13) were also associated with a greater likelihood of a primary care home visit, as was mild/ moderate (OR 1.39, 95\% CI 1.35-1.43) and severe (OR 2.69, 95\% CI 2.59-2.80) functional impairments.

\section{Primary care visits after hours or on weekends and holidays}

Patients living in eastern (OR $0.55,95 \%$ CI $0.53-0.58$ ) or northern Ontario (OR $0.50,95 \%$ CI $0.47-0.53$ ) or in rural locations (OR 0.63 , 95\% CI 0.60-0.65) were less likely to use after-hours primary care (Table 7). Compared with enrolment in enhanced fee-for-service models, enrolment in family health teams (OR 0.40, 95\% CI 0.39-0.41), enrolment in other capitated models (IRR 0.64 , 95\% CI $0.63-$ 0.66), enrolment in other models (OR 0.32 , 95\% CI $0.28-$ 0.37 ) or not being rostered to a physician (OR $0.44,95 \%$ CI 0.41-0.47) reduced the likelihood of an after-hours visit. Patients with severe functional impairments (OR 1.27, 95\% CI 1.22-1.32) were more likely to use after-hours care while patients with dementia (OR $0.80,95 \%$ CI $0.78-0.83$ ) were less likely to do so.

\section{Interpretation}

Publicly funded home care patients with continuing care needs frequently used primary care and other health services within 6 months of assessment. Nearly all the patients visited a primary care physician at least once; however, just under $4 \%$ had a billing for home care coordination, $13 \%$ had a home visit from a primary care physician and $15 \%$ used primary care after hours or on a weekend or holiday. Coordination codes were more common in interprofessional primary care practices while afterhours care was more prevalent in noncapitated practices. Physician home visits were more likely to be received by the oldest and most functionally impaired patients.

A previous study with similar primary care definitions reported a rate of 0.52 primary care physician visits per month among all older adults in Ontario. ${ }^{25}$ Comparing this with the 0.78 visits per month observed in this study suggests that home care patients had around 50\% higher primary care use than a general older adult population. Comparisons with the same study also suggest that home care patients had twice the specialist physician use and 3.5 times the emergency department visits of an older adult population. Despite the frequent primary care use observed in our study, the billing codes specific to primary care coordination with home care were rarely used. This could suggest low levels of coordination possibly because of noted difficulties in communication and lack of integration between home care and primary care. ${ }^{26}$ It may also be the result of lack of awareness of the codes or a sense that the codes are not worth the effort of claiming. Family health teams were considerably more likely than other enrolment models to bill the coordination codes, which could be due to their interprofessional orientation or to the fact that regional planning organizations specifically target family health teams in initiatives to promote coordination.

Older patients with severe functional impairments were much more likely to receive a primary care home visit than those without impairments, which suggests physician home visits are responsive to the functional needs of patients. The proportion of home care patients with severe functional impairments who received a physician home visit $(27.5 \%)$ in our study is similar to the proportion of patients receiving palliative care in Ontario reported to have received a physician home visit in the last 6 months of life $(22 \%){ }^{27}$ Historically part of general practice, physician house calls in Canada have become more frequent recently after falling in frequency in previous decades. ${ }^{28-31}$ Finally, home care patients enrolled in noncapitated primary care models were considerably more likely than those enrolled in capitationbased models to use primary care after hours or on weekends or holidays. This effect has been previously noted, including in a study done in 2005-2006, shortly after the implementation of the first capitation models in Ontario. ${ }^{32}$ Our results suggest that the effect has persisted over time and that primary care model types may be influencing access to after-hours care.

\section{Limitations}

Our study has some important limitations. Despite the rich clinical data available in our index assessment, we were not able to determine the specific clinical reason(s) a patient was receiving home care or the focus of coordination between primary care and home care. The degree to which our billing code based measure of coordination between primary care and home care underrepresents the true level of coordination cannot be ascertained by this study and would require qualitative, primary data collection. Given the overall low prevalence of the codes and the low likelihood that these codes would be billed in the absence of coordination, misclassification of coordination would probably move in the direction of reducing sensitivity while maintaining a high specificity and positive predictive value. Finally, findings associated with Ontariospecific primary care models or billing codes may have lower generalizability.

\section{Conclusion}

We found that home care patients with continuing care needs in Ontario frequently visited a primary care physician. Billing codes specific to coordination between primary care and home care were rarely used, although use of the codes may underrepresent the true level of coordination, but they were more commonly used in interprofessional primary care practices. Physician home visits were more likely to be received by the oldest and most functionally impaired patients, suggesting responsiveness to patient needs. After-hours primary care was more commonly received by patients enrolled in noncapitated 
Table 6: Multivariable logistic regression of home visits from primary care physicians

\begin{tabular}{|c|c|c|c|}
\hline Variable & No. of patients & $\begin{array}{l}\text { Unadjusted odds ratio } \\
(95 \% \mathrm{Cl})\end{array}$ & $\begin{array}{c}\text { Adjusted odds ratio } \\
\qquad(95 \% \mathrm{Cl})\end{array}$ \\
\hline \multicolumn{4}{|l|}{ Sex } \\
\hline Female & 83978 & $1.06(1.04-1.09)$ & $1.05(1.02-1.08)$ \\
\hline \multicolumn{4}{|l|}{ Age, yr } \\
\hline $19-59$ & 23520 & 1.00 (ref.) & 1.00 (ref.) \\
\hline $60-69$ & 25957 & $1.29(1.21-1.39)$ & $1.34(1.25-1.44)$ \\
\hline $70-79$ & 47410 & $1.73(1.63-1.84)$ & $1.80(1.69-1.92)$ \\
\hline $80-89$ & 86717 & $2.50(2.37-2.65)$ & $2.63(2.47-2.79)$ \\
\hline$\geq 90$ & 42450 & $3.94(3.71-4.17)$ & $3.89(3.65-4.14)$ \\
\hline \multicolumn{4}{|l|}{ Region* } \\
\hline Central & 93217 & 1.00 (ref.) & 1.00 (ref.) \\
\hline East & 42276 & $0.76(0.73-0.79)$ & $0.82(0.79-0.85)$ \\
\hline North & 19392 & $0.54(0.51-0.57)$ & $0.61(0.58-0.65)$ \\
\hline South & 71169 & $1.03(1.00-1.06)$ & $1.00(0.97-1.03)$ \\
\hline \multicolumn{4}{|l|}{ Rurality $\dagger$} \\
\hline Rural & 30584 & $0.74(0.71-0.77)$ & $0.88(0.84-0.92)$ \\
\hline \multicolumn{4}{|l|}{ Patient enrolment model type } \\
\hline Enhanced fee-for-service & 73150 & 1.00 (ref.) & 1.00 (ref.) \\
\hline Family health team & 75031 & $0.75(0.72-0.77)$ & $0.78(0.76-0.81)$ \\
\hline Other capitation & 64908 & $0.84(0.81-0.86)$ & $0.81(0.79-0.84)$ \\
\hline Other & 8403 & $0.79(0.72-0.86)$ & $1.03(0.93-1.14)$ \\
\hline Not enrolled & 4562 & $1.00(0.94-1.07)$ & $1.03(0.96-1.10)$ \\
\hline \multicolumn{4}{|l|}{ Home care services } \\
\hline Personal support & 162276 & $1.94(1.88-2.00)$ & $1.46(1.41-1.51)$ \\
\hline Nursing & 80636 & $1.84(1.79-1.88)$ & $2.08(2.02-2.13)$ \\
\hline \multicolumn{4}{|l|}{ Function } \\
\hline Independent/supervision & 127725 & 1.00 (ref.) & 1.00 (ref.) \\
\hline Mild/moderate impairment & 72220 & $1.65(1.61-1.70)$ & $1.39(1.35-1.43)$ \\
\hline Severe impairment & 26109 & $3.70(3.58-3.82)$ & $2.69(2.59-2.80)$ \\
\hline \multicolumn{4}{|l|}{ Cognition } \\
\hline Independent/supervision & 85613 & 1.00 (ref.) & 1.00 (ref.) \\
\hline Mild/moderate impairment & 121081 & $1.40(1.36-1.44)$ & $1.09(1.06-1.13)$ \\
\hline Severe impairment & 19360 & $2.06(1.97-2.14)$ & $1.15(1.10-1.22)$ \\
\hline \multicolumn{4}{|l|}{ Mood } \\
\hline No symptoms & 108918 & 1.00 (ref.) & 1.00 (ref.) \\
\hline Some symptoms & 59684 & $1.02(0.99-1.05)$ & $1.02(0.99-1.06)$ \\
\hline Daily symptoms & 57452 & $1.10(1.06-1.13)$ & $1.10(1.07-1.14)$ \\
\hline \multicolumn{4}{|l|}{ Chronic conditions } \\
\hline Congestive heart failure & 29875 & $1.36(1.31-1.40)$ & $1.03(0.99-1.07)$ \\
\hline $\begin{array}{l}\text { Chronic obstructive pulmonary } \\
\text { disease }\end{array}$ & 44209 & $1.04(1.01-1.08)$ & $1.08(1.04-1.12)$ \\
\hline Dementia & 58413 & $1.22(1.18-1.25)$ & $0.91(0.88-0.94)$ \\
\hline \multicolumn{4}{|l|}{ No. of medications } \\
\hline $0-4$ & 36294 & 1.00 (ref.) & 1.00 (ref.) \\
\hline $5-8$ & 70698 & $1.19(1.14-1.23)$ & $1.06(1.02-1.10)$ \\
\hline$\geq 9$ & 119062 & $1.38(1.33-1.43)$ & $1.16(1.11-1.21)$ \\
\hline
\end{tabular}


Table 7: Multivariable logistic regression of primary care visits after hours and on weekends or holidays

\begin{tabular}{|c|c|c|c|}
\hline Variable & No. of patients & $\begin{array}{l}\text { Unadjusted odds ratio } \\
\qquad(95 \% \mathrm{Cl})\end{array}$ & $\begin{array}{c}\text { Adjusted odds ratio } \\
(95 \% \mathrm{Cl})\end{array}$ \\
\hline \multicolumn{4}{|l|}{ Sex } \\
\hline Female & 83978 & $1.09(1.06-1.11)$ & $1.08(1.04-1.11)$ \\
\hline \multicolumn{4}{|l|}{ Age, yr } \\
\hline $19-59$ & 23520 & 1.00 (ref.) & 1.00 (ref.) \\
\hline $60-69$ & 25957 & $0.95(0.90-1.00)$ & $0.91(0.86-0.95)$ \\
\hline $70-79$ & 47410 & $1.00(0.96-1.05)$ & $0.98(0.94-1.03)$ \\
\hline $80-89$ & 86717 & $1.02(0.98-1.06)$ & $1.00(0.96-1.05)$ \\
\hline$\geq 90$ & 42450 & $1.01(0.97-1.06)$ & $1.00(0.95-1.05)$ \\
\hline \multicolumn{4}{|l|}{ Region* } \\
\hline Central & 93217 & 1.00 (ref.) & 1.00 (ref.) \\
\hline East & 42276 & $0.48(0.46-0.50)$ & $0.55(0.53-00.57)$ \\
\hline North & 19392 & $0.41(0.39-0.43)$ & $0.50(0.47-0.53)$ \\
\hline South & 71169 & $1.13(1.10-1.16)$ & $1.10(1.07-1.13)$ \\
\hline \multicolumn{4}{|l|}{ Rurality† } \\
\hline Rural & 30584 & $0.45(0.43-0.47)$ & $0.63(0.60-0.65)$ \\
\hline \multicolumn{4}{|l|}{ Patient enrolment model type } \\
\hline Enhanced fee-for-service & 73150 & 1.00 (ref.) & 1.00 (ref.) \\
\hline Family health team & 75031 & $0.35(0.34-0.36)$ & $0.40(0.39-0.41)$ \\
\hline Other capitation & 64908 & $0.62(0.60-0.64)$ & $0.64(0.63-0.66)$ \\
\hline Other & 8403 & $0.22(0.19-0.25)$ & $0.32(0.28-0.37)$ \\
\hline Not enrolled & 4562 & $0.41(0.38-0.44)$ & $0.44(0.41-0.47)$ \\
\hline \multicolumn{4}{|l|}{ Home care services } \\
\hline Personal support & 162276 & $1.19(1.16-1.23)$ & $1.12(1.09-1.15)$ \\
\hline Nursing & 80636 & $(1.12-1.17)$ & $1.22(1.19-1.26)$ \\
\hline \multicolumn{4}{|l|}{ Function } \\
\hline Independent/supervision & 127725 & 1.00 (ref.) & 1.00 (ref.) \\
\hline Mild/moderate impairment & 72220 & $1.05(1.03-1.08)$ & $1.00(0.97-1.03)$ \\
\hline Severe impairment & 26109 & $1.48(1.43-1.53)$ & $1.27(1.22-1.32)$ \\
\hline \multicolumn{4}{|l|}{ Cognition } \\
\hline Independent/supervision & 85613 & 1.00 (ref.) & 1.00 (ref.) \\
\hline Mild/moderate impairment & 121081 & $0.91(0.89-0.93)$ & $0.95(0.93-0.98)$ \\
\hline Severe impairment & 19360 & $1.04(1.00-1.09)$ & $1.05(0.99-1.10)$ \\
\hline \multicolumn{4}{|l|}{ Mood } \\
\hline No symptoms & 108918 & 1.00 (ref.) & 1.00 (ref.) \\
\hline Some symptoms & 59684 & $1.04(1.02-1.07)$ & $1.05(1.02-1.08)$ \\
\hline Daily symptoms & 57452 & $1.13(1.10-1.16)$ & $1.12(1.09-1.16)$ \\
\hline \multicolumn{4}{|l|}{ Chronic conditions } \\
\hline Congestive heart failure & 29875 & $1.01(0.98-1.05)$ & $0.97(0.93-1.00)$ \\
\hline $\begin{array}{l}\text { Chronic obstructive pulmonary } \\
\text { disease }\end{array}$ & 44209 & $1.01(0.89-1.04)$ & $1.05(1.02-1.08)$ \\
\hline Dementia & 58413 & $0.81(0.79-0.83)$ & $0.80(0.78-0.83)$ \\
\hline \multicolumn{4}{|l|}{ No. of medications } \\
\hline $0-4$ & 36294 & 1.00 (ref.) & 1.00 (ref.) \\
\hline $5-8$ & 70698 & $1.10(1.07-1.15)$ & $1.11(1.07-1.16)$ \\
\hline$\geq 9$ & 119062 & $1.17(1.13-1.21)$ & $1.18(1.14-1.23)$ \\
\hline
\end{tabular}


primary care models, suggesting models of physician payment may be affecting access to after-hours care. These findings provide important insight into the primary care use of home care patients and can inform future research on how patterns of primary care and home care can influence the health outcomes of home care patients.

\section{References}

1. Rothman AA, Wagner EH. Chronic illness management: What is the role of primary care? Ann Intern Med 2003;138:256-61.

2. Grumbach K. Chronic illness, comorbidities, and the need for medical generalism. Ann Fam Med 2003;1:4-7.

3. Best advice: chronic care management in a patient's medical home. Mississauga $(\mathrm{ON})$ : College of Family Physicians of Canada; 2016.

4. Kastner M, Cardoso R, Lai Y, et al. Effectiveness of interventions for managing multiple high-burden chronic diseases in older adults: a systematic review and meta-analysis. CMA7 2018;190:E1004-12.

5. Stall N, Nowaczynski M, Sinha SK. Systematic review of outcomes from home-based primary care programs for homebound older adults. 7 Am Geriatr Soc 2014;62:2243-51.

6. Mian O, Pong R. Does better access to FPs decrease the likelihood of emergency department use? Results from the Primary Care Access Survey. Can Fam Physician 2012;58:e658.

7. Van Uden CJ, Crebolder HF. Does setting up out of hours primary care cooperatives outside a hospital reduce demand for emergency care? Emerg Med 7 2004;21:722-3.

8. Schoen C, Osborn R, Squires D, et al. New 2011 survey of patients with complex care needs in eleven countries finds that care is often poorly coordinated. Health Aff (Millwood) 2011;30:2437-48.

9. Wilson D, Truman C. Comparing the health services utilization of longterm-care residents, home-care recipients, and the well elderly. Can 7 Nurs Res 2005;37:138-54.

10. Campitelli MA, Bronskill SE, Hogan DB, et al. The prevalence and health consequences of frailty in a population-based older home care cohort: a comparison of different measures. BMC Geriatr 2016;16:133.

11. Sinha S. Living longer, living well. Toronto: Ontario Ministry of Health and Long-Term Care; 2012.

12. The state of seniors bealth care in Canada. Ottawa: Canadian Medical Association; 2016.

13. Williams JI, Young W. A summary of studies on the quality of health care administrative databases in Canada [appendix]. In: Patterns of bealth care in Ontario: the ICES practice atlas. 2nd ed. Ottawa: Canadian Medical Association 1996:339-45

14. Home and community care: how to get help for patients and seniors who need support living at home. Government of Ontario; 2019. Available: https://www. ontario.ca/page/homecare-seniors (accessed 2019 Apr. 25).

15. Home Care Reporting System Data Users Guide 2017-2018. Ottawa: Canadian Institute for Health Information; 2019.

16. Hirdes JP, Bernier J, Garner R, et al. Measuring health related quality of life (HRQoL) in community and facility-based care settings with the interRAI assessment instruments: development of a crosswalk to HUI3. Qual Life Res 2018;27:1295-1309.

17. Fergenbaum J, Bermingham S, Krahn M, et al. Care in the home for the management of chronic heart failure: systematic review and cost-effectiveness analysis. 7 Cardiovasc Nurs 2015;30:S44-51.

18. Clarkson P, Davies L, Jasper R, et al. A systematic review of the economic evidence for home support interventions in dementia. Value Health 2017; 20:1198-1209.

19. Cruz J, Brooks D, Marques A. Home telemonitoring effectiveness in COPD: a systematic review. Int 7 Clin Pract 2014;68:369-78.

20. Green M, Gozdyra P, Frymire E, et al. Geographic variation in the supply and distribution of comprehensive primary care physicians in Ontario, 2014/15. Toronto: Institute for Clinical Evaluative Sciences; 2017.

21. Poss, J. Mind the gap? Looking at reassessment patterns among Ontario longstay home care clients. Proceedings from the 2009 Canadian interRAI Conference; 2009 June 22-24; Halifax (NS).

22. Wedderburn RW. Quasi-likelihood functions, generalized linear models, and the Gauss-Newton method. Biometrika 1974;61:439-47.

23. Hu T, Dattani ND, Cox KA, et al. Effect of comorbidities and medications on frequency of primary care visits among older patients. Can Fam Physician $2017 ; 63: 45-50$
24. Laberge M, Wodchis WP, Barnsley J, et al. Efficiency of Ontario primary care physicians across payment models: a stochastic frontier analysis. Health Econ Rev 2016;6:22.

25. Nie JX, Wang L, Tracy CS, et al. A population-based cohort study of ambulatory care service utilization among older adults. 7 Eval Clin Pract 2010; 16:825-31.

26. Expert Group on Home and Community Care. Bringing care home. Toronto: Ontario Ministry of Health and Long-Term Care; 2015

27. Howard M, Chalifoux M, Tanuseputro P. Does primary care model effect healthcare at the end of life? A population-based retrospective cohort study. 7 Palliat Med 2017;20:344-51.

28. Walkinshaw E. Back to black bag and horse-and-buggy medicine. CMAJ 2011;183:1829-30.

29. Chan BTB. The declining comprehensiveness of primary care. CMA7 2002; $166: 429-34$

30. Office of the Premier. Ontario expanding house call services: McGuinty Government helps seniors stay healthy, stay home longer. Service Ontario Newsroom [Toronto]. 2012 Dec. 11. Available: https://news.ontario.ca/opo/en/2012/12/ ontario-expanding-house-call-services.html (accessed 2012 Dec. 11).

31. Palmer K, Konkin J, Michael N. House calls on the rise in Ontario. Healthy Debate 2017 Aug. 3. Available: https://healthydebate.ca/2017/08/topic/house -calls-rise-ontario (accessed 2018 Nov. 29).

32. Glazier RH, Klein-Geltink J, Kopp A, et al. Capitation and enhanced fee-forservice models for primary care reform: a population-based evaluation. CMA7 2009;180:E72-81.

Affiliations: Department of Health Research Methods, Evidence, and Impact (Jones, Agarwal, Seow, Costa), McMaster University, Hamilton, Ont.; ICES (Bronskill), Toronto, Ont.; Institute of Health Policy, Management and Evaluation (Bronskill), Dalla Lana School of Public Health, University of Toronto, Toronto, Ont.; Departments of Family Medicine (Agarwal), Oncology (Seow), Economics (Feeny) and Medicine (Costa), McMaster University, Hamilton, Ont.

Contributors: Aaron Jones and Andrew Costa conceived the study and developed the design in consultation with the other authors. Aaron Jones completed the analysis and drafted the manuscript. All authors contributed to the interpretation of data, critically revised the manuscript for important intellectual content, approved the final version to be published and agreed to be accountable for all aspects of the work.

Funding: This study was funded by grants from the Canadian Frailty Network (TG2015-15P) and the Canadian Institutes of Health Research (148933). The opinions and conclusions expressed in this article are those of the authors and do not necessarily reflect the views of the contributing centres or funders.

Data-sharing statement: The data set from this study is held securely in coded form at ICES. While data-sharing agreements prohibit ICES from making the data set publicly available, access may be granted to those who meet prespecified criteria for confidential access, available at www. ices.on.ca/DAS. The full data set creation plan and underlying analytic code are available from the authors upon request, with the understanding that the computer programs may rely upon coding templates or macros that are unique to ICES and are therefore either inaccessible or may require modification.

Disclaimer: This study was supported by ICES, which is funded by an annual grant from the Ontario Ministry of Health and Long-Term Care (MOHLTC). The opinions, results and conclusions reported in this article are those of the authors and are independent from the funding sources. No endorsement by ICES or the Ontario MOHLTC is intended or should be inferred. Parts of this material are based on data and/or information compiled and provided by the Canadian Institute for Health Information (CIHI). However, the analyses, conclusions, opinions and statements expressed in the material are those of the authors, and not necessarily those of CIHI.

Supplemental information: For reviewer comments and the original submission of this manuscript, please see www.cmajopen.ca/content/7/2/ E360/suppl/DC1. 